\title{
Theoretical Framework on the Role of Knowledge Management for Students on Academic Performance
}

\author{
Anh Duc Do* Thi Thu Hoai Le Thi Thu Huyen Dinh Thi Mai Thao Hoang \\ School of Trade and International Economics, National Economics University, 207 Giai Phong Street, Hai Ba \\ Trung District, Ha Noi, Vietnam
}

\begin{abstract}
Knowledge management is a developing sector that has received lots of consideration and support from the community which is industrial. Knowledge management is a young academic field which has not been built up a systematized and unified framework. This paper reviews the role of knowledge management for students on academic performance by using the structural equation modeling. Through applying knowledge management in the study process can help students to gain better results. As a result, it can be expected to shed light on the relative importance of knowledge management on students' academic performance.
\end{abstract}

Keywords: Knowledge management, Academic performance, digital economy

DOI: $10.7176 / \mathrm{IKM} / 11-2-05$

Publication date:March $31^{\text {st }} 2021$

\section{Introduction}

Knowledge management is a developing sector that has received lots of consideration and support from the community which is industrial (Rubenstein-Montano et al., 2001) because knowledge is considered to be an invaluable asset and a major source for development of each nation (Anantatmula, 2007). Moreover, the rapid advancements of technology and innovations have enhanced the competition among organizations (Sunassee and Sewry, 2002), therefore, knowledge management becomes an important issue to achieve the goals of organizations, particularly educational organizations which relate to education and training (Naser et al., 2016). There are many researches that have shown that applying knowledge management in educational organizations will bring benefits for academic achievements (Kidwell, Vander Linde and Johnson, 2000; Buckley, 2012; Zwain et al., 2012). These benefits become clearer when HEIs are changing from a public service to a marketdriven one (Kettunen, 2003).

In a knowledge economy, knowledge management has been recognized as one of the determining elements for innovation and competitive advantage (Darroch, 2005; Dasgupta et al., 2009). In Viet Nam, the difference between training programs and the needs of employers leads to current high levels of unemployment among recent university graduates, which lead to the necessity to improve the quality of teaching and learning at universities (Dao and Hayden, 2010). To meet this requirement, it is necessary to adopt KM techniques in curriculum development. However, knowledge management is still a young academic field which has not been built up a systematized and unified framework. In addition, a myriad of frameworks have been developed for knowledge management around the world but the sector has slowly formulated a widely accepted, comprehensive framework for knowledge management. To fill this gap, the paper shows practical evidence of the effect of knowledge management on students' academic performance. Besides, the paper also contributes to knowledge management and academic performance literature by exploring knowledge management's impacts on student's academic performance in Vietnam.

The rest of the paper is organized as follows: Section 2, shows the literature reviews of the effect of knowledge management on students' academic performance. Section 3 mentions research methods based on SEMs (Structural Equation Modeling) and conclusion on research result in section 4.

\section{Literature reviews of the effect of knowledge management on students' academic performance}

Theoretically, the relationship between knowledge management and students' academic performance cannot be explained by one theory. Eisner's study illustrated that outcomes are wide overarching results of studying which are not fulfilling the strict criteria which necessarily apply to behavioral goals, where the following research are clear and particular statements of expectant behavior including the provisos under which the behavior will happen and acceptable performance standards. This do not suggest that the utilization of outcomes in designing curriculum exclude a statement of intent relating what one will end up with, but it is more true that, 'the exact sizes of the outcomes cannot be confirmed to the level of clarity or particularity that teaching targets need to have' (Eisner, in Popham et al., 1969, ). When showing what the core nature of these outcomes might be, Eisner's work (1979) offers a framework which is integrated and he suggests that the results of an experience of learning include the outcomes of specific subject, learner and specific teacher.

According to Cantner and Joel (2007), the definition of knowledge management (KM) embraces activities of an organization to manage assets about knowledge. Moreover, there are definitions of knowledge 
management but in general, its purpose is to raise a corporation's innovation and economic activities. Ratherly, $\mathrm{KM}$ is considered to be a problem-solving device, which improves knowledge exploration and knowledge exploitation success of organizations (Swan et al., 1999). Therefore, KM becomes more important: it can be considered as a managerial instrument which can support the essential process of creating and sharing knowledge for organizations, individuals and especially for students in university. Furthermore, Spender (1996) indicated that tacit knowledge is not yet abstracted from practice because it is necessary to innovation (Grant, 1996; Hall, 1993; Nonaka et al., 1995) and also focus on Knowledge Management. Especially, tacit knowledge often appears in an organization's routinized and unmodified workflow. From that point, KM can be said that it is a process which transfers tacit knowledge to explicit knowledge.

From projects proposed by Davenport et al. (1998), Rowley (1999) defined knowledge management is to gain the objectives of organization by exploiting and developing the knowledge assets. Management includes all of those processes related to the identification, sharing and creation of knowledge. He suggested that it is important for organizations to clearly identify the central objective, levels and scope of knowledge management, technologies and techniques used for knowledge management, as well as the role of organization.

Hlupic, Pouloudi and Rzevski (2002) mentioned and discussed basic definitions of knowledge management and discussed that $\mathrm{KM}$ is a complex field that comprises different, hard and abstract aspects: technical problems about KM tools, organizational problems associated with the structure, culture and context within which these tools can be used and the educational organization that may result from their use and basic epistemological problems about the approach and definition to the study of KM.

Jennex (2005) presented the concept of knowledge management (KM), he also discussed tacit knowledge, explicit knowledge, KM systems, KM technology, issues and aspects related to KM. The book has gathered the most basic theoretical issues of KM. The book presented 20 cases on the implementation of KM in businesses and industries settings as well as global contexts. Jennex (2005) defined the proceeding of scrupulously applying knowledge from experiences of decision-making to current and future decision-making activities with the purpose of enhancing the organization's efficiency is knowledge management. This notion allows us to determine the objectives of KM as: Identify Critical Knowledge, Acquire Critical Knowledge in a Knowledge Base or Organizational Memory, Share the stored Knowledge, Apply the Knowledge to appropriate situations, Determine the effectiveness of using the applied knowledge, Adjust Knowledge use to improve effectiveness.

There are some studies that showed knowledge management has a good effect on improving organizational effectiveness (Zaied et al., 2012; Naser et al., 2016). Zaied (2012) illustrated that elements of Knowledge Management Infrastructure comprises: technology, structure, culture and human resources. The study also stated 4 elements of knowledge management are conversions, acquisitions, protections and applications storing. This research also investigated the role of knowledge management in ameliorating the organizational effectiveness in some organizations in Egypt and solved its relationship with performance improvement. As follows, significant relationship between knowledge management elements and performance improvement measures, which proved organizational knowledge's quality used in decision-makings in the organizations. The article also shows the role of concentrating on building a knowledge environment formed by appropriate factors of Knowledge Management Infrastructure.

Naser et al. (2016) assessed knowledge management maturity (KMM) at HEI to determine variables which have the most effect on KM that develop the total organization's effectiveness on Al-Azhar University in Gaza strip, Palestine. The research is based on Asian productivity organization model that was used to assess KMM. The authors developed the second dimension used to assess high performance. The controlled sample was (364). Data analysis and hypothesis testing were assessed by many statistical tools, including reliability Correlation using Cronbach's alpha, "ANOVA", Simple Linear Regression and Step - Wise Regression. The research suggested that KMM is suitable for measuring and results in improving high performance. The university maturity level is appreciated in level three by KMM assessment. Moreover, the main and sub hypotheses are also supported in the study. Processes, KM leadership, People, KM Outcomes, Knowledge Process are considered to be the most essential factors affecting high performance. In addition, the current study's uniqueness is due to the virtue of its nature, scope and way of implied investigation, since it is the first research at HEI in Palestine using the Asian productivity model for exploring the status of KM. 5 factors are mentioned to measure KM: Processes, KM leadership, People, KM Outcomes, Knowledge Process. It also showed 5 levels of knowledge including reaction, beginning, widening, screening, maturity. The research mentioned KM in high education context but has not focused on assessing the impact of KM to the student's academic performance. In educational institutions, $\mathrm{KM}$ is the principal objectives of those organizations, from that, they can manage and create new knowledge through activities and technical practices to connect learners from different administrative levels and sections. This process establishes working groups and relationships which create sharing and exchange of knowledge they possess, support students in learning processes, then improve and develop individual and organizational performance. Measuring KMM is an essential process and should not be ignored.

Kianto et al. (2019) assessed the importance of knowledge management and found its effect on knowledge 
work productivity. This study also showed the knowledge management include 3 elements: knowledge utilization, knowledge sharing and knowledge creation. Knowledge creation is a process and it is also an organizational ability to generate knowledge in the format of new ideas and solutions (Andreeva and Kianto, 2011; Kianto et al., 2016). Knowledge sharing is the movement of knowledge between the dissimilar units and factors in an institution (Andreeva and Kianto, 2011; Hooff and De Ridder, 2004; Nonaka, 1994). And knowledge utilization is an organization's mechanism to store, regain, access and utilize knowledge efficiently for strategic aims (Gold et al., 2001). The research points out two important elements of knowledge management: knowledge creation and knowledge use which have effect on the work productivity and knowledge utilization in a positive and meaningful way; while knowledge sharing does not affect much productivity and knowledge utilization. Demographic factors such as sex, management position or academic level do not adjust the connection between knowledge management and knowledge labor productivity.

In the light of above perspectives, there are a lot of studies that have investigated the importance of KM as well as suggest solutions to apply KM in specific contexts. (Shafique, 2015; Daniel E and O'Leary, 1998; Mahdia et al., 2017; Rowley et al., 2017; Pham et al., 2021).

For businesses, Daniel E and O'Leary (1998) point out that in the increasingly competitive landscape, businesses must create a system that captures knowledge and supplies to all members of their businesses. The article showed some methods of processing data and using models to make knowledge management widely available in the enterprise. The study showed that KM practices are measured through information technology, organization and knowledge positively affect the business's operations. The authors indicated that enterprise KM requires formally managing knowledge resources to access and reuse of knowledge by using advanced information technology. The vital purpose of business $\mathrm{KM}$ is to transfer knowledge, then it can be used, accessible and reusable to the enterprise. However, the article has not shown the factors that negatively impact on knowledge management activities in organizations and how to apply it effectively.

With an educational organization, Shafique (2015) emphasized the importance of knowledge management and how to apply knowledge management to Saudi Arabia applying the Library Knowledge Management Center (LKMC) model to promote higher education in here. In addition, knowledge management can provide an intelligent environment for those who work in educational organizations. Based on the article, libraries are established and linked resources and change the approach of information, enabling individuals to efficiently search for information.

Other studies, Rowley et al. (2017) illustrated that although attendees can debate knowledge management, none of universities had a knowledge management strategy. Moreover, the study indicated that KM has three main factors: knowledge transfer, knowledge sharing and knowledge creation and it is essential for KM to support universities in teaching, knowledge transfer and research, but also recognizes that the approaches of high education are still inconsistent and passive. In addition, Rowley et al. (2017) said that a key prerequisite for the success of knowledge management is a comprehension of the sectors that encourage or inhibit knowledge creation, transfer and sharing in high education. Enablers for knowledge management are elements or institutional mechanisms that facilitate knowledge sharing, stimulate knowledge creation (Lee and Choi, 2003), and encourage knowledge transfer (Gera, 2012).

Zwain et al. (2017) showed the connection between factors of quality management, knowledge management and the result of educational organization related to learning outcomes. The article indicated the factors of quality management have a positive effect on knowledge management and academic performance. A new finding of this study showed that knowledge management is the association between quality management and learning outcomes. Besides, the research confirmed that when the core elements of quality management are implemented integrally, the knowledge management process can achieve a higher level. This is one of the few studies that has mentioned the relationship between knowledge management and students' learning outcomes, but it still has limitations as it excludes other factors between different institutions in different disciplines, indicators that measure student outcomes are subjective indicators and only use Baron and Kenney methods to analyze data.

Furthermore, it is clear that applying knowledge management in educational organizations will bring benefits for academic achievements (Buckley, 2012; Zwain et al., 2012). Because the economy is in consecutive changes, organizations and individuals have to face up with the large number of knowledge unprocessed, the selection and processing of information is extremely important.

\section{Proposed Model}

After researching models related to KM in organizations, universities and individuals, the study proposes SEM (Structural Equation Modeling) to assess the impact of factors of KM on the academic performance of students. Because the study is used for developing theories in exploratory research, Partial Least Square SEM (PLS-SEM) is chosen.

According to the literature review and research, this study has considered knowledge sharing, knowledge 
collection, knowledge creation and knowledge application as knowledge management elements and proposed a structural model of the relationships between knowledge management and students' academic performance in universities.

Knowledge sharing is exchanging knowledge (skills, understanding and experience) between individuals who work together in an institution (Arntzen et al., 2009).

Knowledge collection is the absorption of knowledge. It also comprises natural categories such as knowledge masses, cultural transmission and learners, which request a re-awareness of knowledge as social and cultural. These cultural and social activities depend on teachers' knowledge, events and knowledge organization (Salo, 2011).

Knowledge application is the process of presenting and applying knowledge which is gathered and validated to impact on determining, planning policies, solving problems or giving solutions for human demands. This element utilizes chances to explore knowledge. Knowledge must undergo the process of setting up, transformation, and maintenance in use and action (O'Toole, 2004). Knowledge application is the utilization or combination of gained knowledge in the design or delivery organizational produce and services (Mothe et al., 2017).

Knowledge creation is the ability of the organization to create new and advantageous ideas and solutions. This factor involves many ranges of organizational operations, including reality of management, process technology and product (Nonaka et al., 2009).

The model can be determined as follows (see Figure 1):

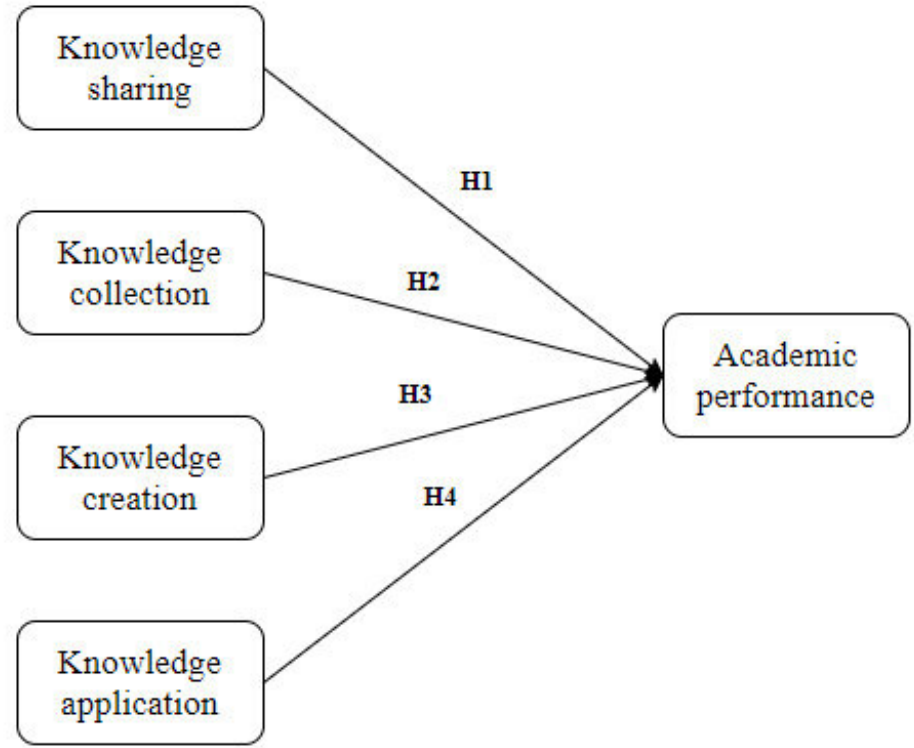

Figure 1. Research model

This research presents the following hypotheses:

H1. Knowledge sharing activities significantly impact on academic performance

H2. Knowledge collection activities significantly impact on academic performance

H3. Knowledge creation activities significantly impact on academic performance

H4. Knowledge application activities significantly impact on academic performance

\section{Methodology for evaluating the impact of KM on students' academic performance}

There are two common methods to estimate linear structural models: CB - SEM (Covariance-based SEM) and PLS - SEM (Partial least squares SEM). Structural Equation Modeling (SEM) has been developed for a long time and plays an essential role in the domain of academic and corporate governance practice. PLS - SEM would be a better option for analyses without theoretical support, analyses related to exploring relationships between variables, analyzes focusing on predicting key target variables and analyses looking for key driver variables. Two purposes of developing PLS - SEM are: (i) conceptual exploration and forecast and (ii) checking and verifying connection between definitions according to theories (replacing CB - SEM).

Based on the literature discussed above, PLS-SEM model was used for the new methodology for evaluating the impact of knowledge management on academic performance. The reason for choosing this model is the number of samples is small and the data does not have a normal distribution. PLS-SEM model is used to provide an overall picture of knowledge management and academic performance and then is employed to quantify the effect of knowledge management and academic performance. 


\section{Conclusion}

This research indicates a framework for the role of knowledge management on students' academic performance. Based on the literature review, the study also proposed a methodology for assessing the effect of knowledge management on students' academic performance in Viet Nam. As a result, it can be expected to shed light on the relative importance of knowledge management on students' academic performance. It provides implications to policies to improve the academic performance of students at University.

\section{References}

Alimohammadlou, M., \& Eslamloo, F. (2016), Relationship between Total Quality Management, knowledge Transfer and knowledge Diffusion in the academic settings, Procedia-Social and Behavioral Sciences, Vol. 230, pp. 104-111.

Bock, G.-W., Zmud, R. W., Kim, Y.-G., \& Lee, J.-N. (2005). Behavioral intention formation in knowledge sharing: Examining the roles of extrinsic motivators, social-psychological forces, and organizational climate. MIS quarterly, 87-111.

Bolisani, E., \& Bratianu, C. (2018). The elusive definition of knowledge. In Emergent knowledge strategies (pp. 1-22). Springer, Cham.

Buckley, S. (2012). Higher education and knowledge sharing: From ivory tower to twenty-first century. Innovations in Education and Teaching international, 49(3), 333-344.

Bukht, R., \& Heeks, R. (2017). Defining, conceptualising and measuring the digital economy. Development Informatics working paper, (68).

Cantner, U., \& Joel, K. (2007). Functional chains of knowledge management: effects on firms' innovative performance (No. 2007, 080). Jena Economic Research Papers.

Dalkir, K. (2005). The knowledge management cycle. Knowledge management in theory and practice. Oxford: Elsevier, 25-46.

Davenport, T. H., \& Prusak, L. (1998). Working knowledge: How organizations manage what they know. Harvard Business Press.

Davenport, Thomas H., and Philip Klahr, "Managing customer support knowledge." California management review 40.3 (1998): 195-208.

Gera, R. (2012), "Bridging the gap in knowledge transfer between academia and practitioners", International Journal of Educational Management, Vol. 26 No.3, pp. 252-273.

Grant, R. M. (1996). Toward a knowledge-based theory of the firm. Strategic Management Journal, 17(S2), $109-122$

Hlupic, V., Pouloudi, A., \& Rzevski, G. (2002), Towards an integrated approach to knowledge management: 'hard', 'soft 'and 'abstract' issues, Knowledge and Process Management, Vol. 9(2), pp. 90-102.

Jennex, M. E. (Ed.). (2005). Case studies in knowledge management. IGI Global.

Kianto, A., Shujahat, M., Hussain, S., Nawaz, F., \& Ali, M. (2019). The impact of knowledge management on knowledge worker productivity. Baltic Journal of Management.

Lee, H. and Choi, B. (2003), "Knowledge management enablers, processes, and organizational performance: an integrative view and empirical examination", Journal of Management Information Systems, Vol. 20 No. 1, pp. 179-228.

Lee, V. H., Foo, A. T. L., Leong, L. Y., \& Ooi, K. B. (2016). Can competitive advantage be achieved through knowledge management? A case study on SMEs. Expert Systems with Applications, 65, 136-151.

Lopatina, E., Damani, Z., Bohm, E., Noseworthy, T. W., Conner-Spady, B., MacKean, G., ... \& Marshall, D. A. (2017). Single-entry models (SEMs) for scheduled services: towards a roadmap for the implementation of recommended practices. Health Policy, 121(9), 963-970.

Mahdi, O. R., Nassar, I. A., \& Almsafir, M. K. (2019). Knowledge management processes and sustainable competitive advantage: An empirical examination in private universities. Journal of Business Research, 94, 320-334.

Martins, V. W. B., Rampasso, I. S., Anholon, R., Quelhas, O. L. G., \& Leal Filho, W. (2019). Knowledge management in the context of sustainability: Literature review and opportunities for future research. Journal of cleaner production, 229, 489-500.

Mothe, C., Nguyen-Thi, U. T., \& Triguero, Á. (2018). Innovative products and services with environmental benefits: design of search strategies for external knowledge and absorptive capacity. Journal of Environmental Planning and Management, 61(11), 1934-1954.

Naser, S. S. A., Al Shobaki, M. J., \& Amuna, Y. M. A. (2016). Measuring knowledge management maturity at HEI to enhance performance-an empirical study at Al-Azhar University in Palestine.

Nonaka, I., \& Von Krogh, G. (2009). Perspective-Tacit knowledge and knowledge conversion: Controversy and advancement in organizational knowledge creation theory. Organization science, 20(3), 635-652.

O’Dell, C. (1996, December). A current review of knowledge management best practice. In conference on 
knowledge management and the transfer of best practices, Business Intelligence, London.

O'Leary, D. E. (1998). Enterprise knowledge management. Computer, 31(3), 54-61.

Ong, H. B., Yeap, P. F., Tan, S. H., \& Chong, L. L. (2011). Factors influencing knowledge sharing among undergraduate students: A Malaysian perspective. Industry and Higher Education, 25(2), 133-140.

Pham, N. T., Do, A. D., Nguyen, Q. V., Ta, V. L., Dao, T. T. B., Ha, D. L., \& Hoang, X. T. (2021). Research on Knowledge Management Models at Universities Using Fuzzy Analytic Hierarchy Process (FAHP). Sustainability, 13(2), 809.

Probst, G. J. (1998). Practical knowledge management: A model that works. PRISM-CAMBRIDGE MASSACHUSETTS-, 17-30.

Rowley, J. (1999). What is knowledge management?. Library management.

Rubenstein-Montano, B., Liebowitz, J., Buchwalter, J., McCaw, D., Newman, B., Rebeck, K., \& Team, T. K. M. M. (2001). A systems thinking framework for knowledge management. Decision support systems, 31(1), 516.

Salo, N. (2011). Knowledge management in education in Indonesia: An Overview. Global Journal of human social science, 11(1).

Shafique, F. (2015), Knowledge management in higher education: Applicability of LKMC model in saudi Universities, Computer Science \& Information Technology (CS \& IT), pp. 175-181.

Spender, J. C. (1996). Making knowledge the basis of a dynamic theory of the firm. Strategic management journal, 17(S2), 45-62.

Spender, J. C., \& Grant, R. M. (1996). Knowledge and the firm: Overview. Strategic management journal, $17(\mathrm{~S} 2), 5-9$.

Sunassee, N. N., \& Sewry, D. A. (2002, September). A theoretical framework for knowledge management implementation. In Proceedings of the 2002 annual research conference of the South African institute of computer scientists and information technologists on Enablement through technology (pp. 235-245).

Yuen, T. J., \& Majid, M. S. (2007). Knowledge - sharing patterns of undergraduate students in Singapore. Library Review.

Zaied, A. N. H., Hussein, G. S., \& Hassan, M. M. (2012). The role of knowledge management in enhancing organizational performance. International Journal of Information Engineering and Electronic Business, $4(5), 27$

Zwain, A. A. A., Lim, K. T., \& Othman, S. N. (2017). TQM and academic performance in Iraqi HEIs: associations and mediating effect of KM. The TQM Journal.

Zwain, A. A., Lim, K. T. and Othman, S. N. (2012), "Knowledge management processes and academic performance in Iraqi HEIs: an empirical investigation", International Journal of Academic Research in Business and Social Sciences, Vol.2 No.6, pp.1-21. 